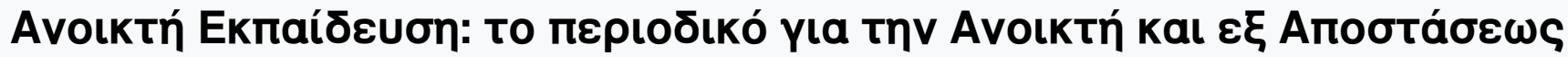

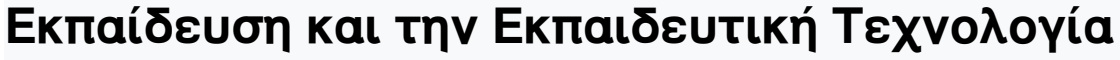

Tón. 16, Ap. 1 (2020)

Open Education: The Journal for Open and Distance Education and Educational Technology

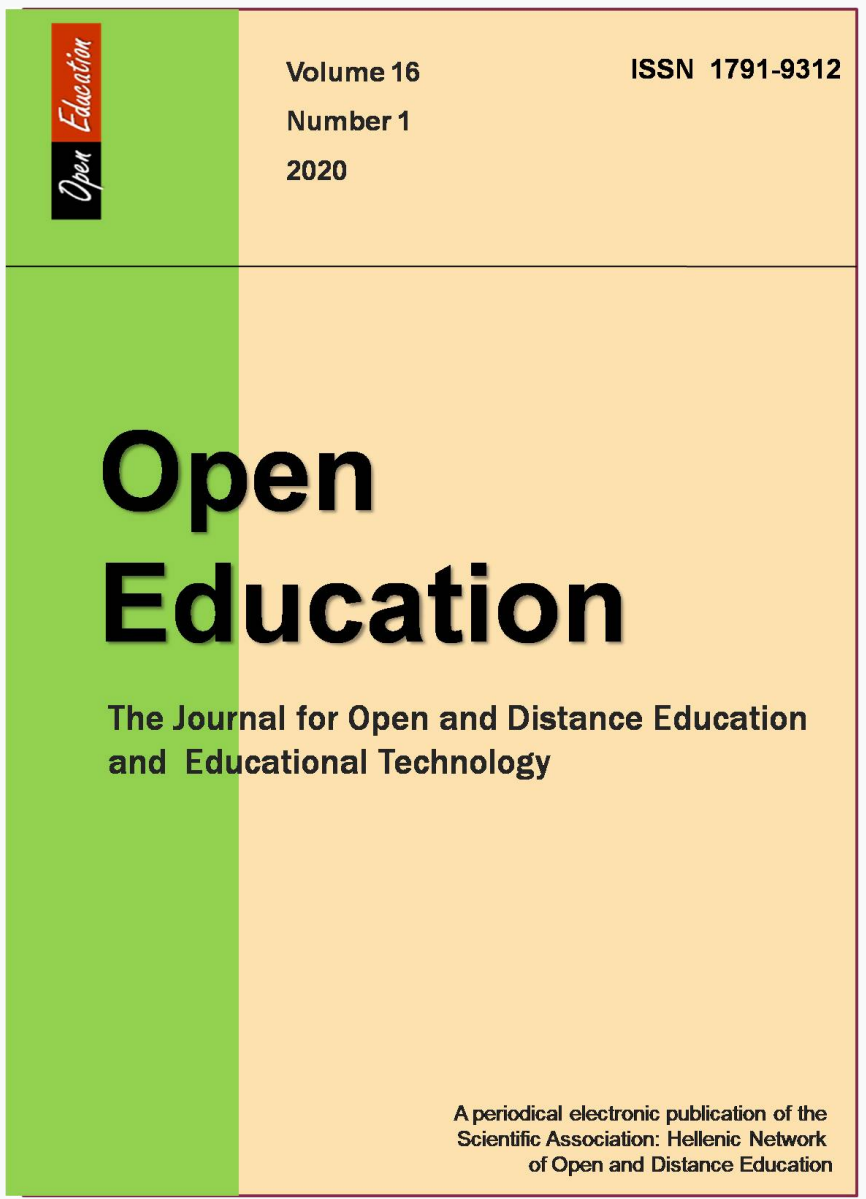

Teaching through written assignments in the Open University: an approach to the "voice" of postgraduate students on Instructional Discourse

Gerasimos S. Koustourakis

doi: $10.12681 /$ jode.23156

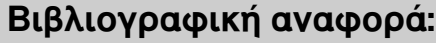




\title{
Teaching through written assignments in the Open University: an approach to the "voice" of postgraduate students on Instructional Discourse
}

Gerasimos S. Koustourakis Professor

Department of Educational Sciences and Early Childhood Education, University of Patras koustourakis@upatras.gr http://orcid.org/0000-0001-8499-5399

\begin{abstract}
This paper aims to approach and analyse students' views on educational work that is carried out through the preparation of and feedback on written assignments, which constitute a fundamental element of the Open University teaching procedure, by making use of the concepts of instructional discourse and regulative discourse from Basil Bernstein's theory, as well as the concept of institutional habitus. The research data were collected through semi-structured interviews with a sample of postgraduate students who were following the "Open Distance Learning" Module with the Hellenic Open University (HOU). The research findings reveal that the students would like Visible Pedagogies to be implemented during the conduct of distance teaching through written assignments. In particular, in contrast to the regulations of the HOU institutional habitus they would like to be provided with a great deal of time to produce their assignments, and for their assignments to be corrected by their tutors within a week. In addition, the students would like the requirements concerning the selection of the educational material they should consult, and the sequencing of their text, as well as the assessment criteria used to evaluate their written effort, to be made clear and obvious, as much prior to the preparation of their papers, as during correction of them.
\end{abstract}

\section{Keywords}

Written assignments; Open University; instructional discourse; regulative discourse

\section{Introduction}

Written assignments are a defining factor of the learning journey of students at the Open Universities since they influence their learning effort and the outcome of their learning trajectory at these particular institutions (Anderson, 2007; Holmberg, 2002; Race, 1999; Robertson, 2014). This is because they constitute the chief means of formulating assessment that contributes to how students are informed of their progress, and they are closely linked to the phenomenon of dropping-out (Chetwynd \& Dobbyn, 2011; Gregori, P., Martinez, \& Moyano-Fernandez, 2018; Maliotaki, 2019; Pierrakeas, Xenos, Panagiotakopoulos, \& Vergidis, 2004; Simpson, 2018).

Scientific literature on written assignments in open distance learning is rich and focuses on detecting teachers' and learners' views on questions of their effect on the course of students' long distance studies, the procedure and the difficulties encountered in preparing them, as well as the quality and usefulness of feedback for 
the students (see: Blair \& McGinty, 2013; Calfoglou, Georgountzou, Hill, \& Sifakis, 2011; Chatzinikita \& Vorvulas, 2019; Cokwe, 2015; Kofou, 2019; Kreonidou \& Kazamia, 2019; Lizzio \& Wilson, 2008; Mirador, 2018; Poulos \& Mahony, 2008; Walker, 2009). A gap in research is observed in the sociological approach to the institution of written assignments that constitute a chief element for the formation of pedagogical practices in the Open Universities (Koustourakis, 2006, 2015; Koustourakis, Panagiotakopoulos, \& Vergidis, 2008). Through relevant scientific studies the power and control relationships that are implemented between tutorstudents and which influence the quality as much of the interaction between them as of the teaching work that is developed at the Open University, can be revealed and understood (Bernstein, 2000; Morais, 2002).

This research paper aims at a sociological approach to and analysis of the voice, that is to say, the views, of postgraduate students at the Hellenic Open University (HOU) on the implementation of 'instructional discourse', in other words, teaching, through written assignments of the essay type. The investigation of the students" "eye" on the institution of written assignments is important since these assignments play a crucial role in the course of their studies with the Open University, revealing at the same time the way teaching and pedagogical practices are implemented in each institution (Blair \& McGinty, 2013; Gravett \& Petersen, 2002; Koustourakis, 2015; Race, 1999). Furthermore, from the relevant studies the problematic situations that are an obstacle in the learning process and which downgrade the quality of distance educational provision can be discovered. Confronting this kind of problem may require adaptation as much of the teachers' pedagogical work, as of aspects of the institution's institutional habitus (Burke \& Pieterick, 2010; Chetwynd \& Dobbyn, 2011).

The paper begins with the section on theoretical observations in which the sociological theoretical concepts that are utilised in this study are analysed and this is followed by the section with the research questions and methodology. The results are then presented and analyzed and the paper closes with the section of the Discussion and Conclusion.

\section{Theoretical Pointings out}

The organizational and educational culture that takes shape in an institution providing distance education, like the HOU, promotes its own institutional habitus and influences the tutors and students, frequently restructuring their habitus concerning the way they understand and implement their educational work (Ingram, 2009; Reay, David, \& Ball, 2005; Smyth \& Banks, 2012; Thomas, 2002). Habitus is the result of the individual's socialization under the influence, initially, of his family environment (primary habitus) and then his educational journey (secondary habitus), such as study with the HOU, and the practice of a profession (tertiary habitus), as is the case with teachers at the Open Universities (Bourdieu, 1986, 1990; Bourdieu \& Wacquant, 1992; Koustourakis, 2017).

The formation of institutional habitus at the HOU is linked to the selection of progressive pedagogies as adult students are placed at the centre of the educational process and the tutors are called on to support them in their learning effort (Bernstein, 2000; Koustourakis, 2015; Koustourakis et al., 2008; Lionarakis, 1998). Written assignments are a crucial element of HOU studies, contributing to the activation of the learner in the learning process since, as happens too in other Open Universities, preparing them demands creative study and utilization as much of educational material as of supplementary bibliographical sources especially on postgraduate study 
programmes (Anderson, 2007; Bei, Mavroidis, \& Giossos, 2020; Nicol \& McFarlaneDick, 2006; Robertson, 2014). Moreover, written assignments are a factor in the implementation of the teaching and communicative role of the tutor (Holmberg, 2002; Lionarakis, 1998; Race, 1999). Based on the institutional habitus of the HOU the tutor-students interaction based on the written assignments is carried out as follows (HOU, 2019; Koustourakis, 2015): a) during the Contact Sessions the tutor should explain the topic of the written assignments to the students; b) the students can communicate with the tutor using all available technological means (e.g. telephone, email, forums) for clarifications and learning support during the writing of their assignments, as well as to discuss the results of the feedback they received; and c) the HOU gives the tutor 21 days from the deadline for the submission of the written assignments to send feedback comments to the students. In addition the tutors are asked to make corrections on the texts of the students' assignments.

The tutor-students interaction at the Open University can be approached in sociological terms using the concepts of "instructional discourse" (I.D.) and "regulative discourse" (R.D.) from the theory of Basil Bernstein. These two discourses are elements of the concept of "framing" (F), which is illustrated as follows (Bernstein, 2000): F=I.D./R.D.

R.D. contributes to the analysis of the shaping of the communicative (hierarchical) tutor-student relationships. Their roles in these relationships are asymmetrical (Bernstein, 1990, 2000). It also contributes to the understanding of the quality of the interactive relationships between them, which are determined by rules for the shaping of accepted means of communication, behaviour and social relations.

I.D., adapted to the institution of written assignments in the case of the Open Universities, is composed of the following factors (Bernstein, 1990, 2000, 2004; Koustourakis, 2017; Morais, 2002):

a) The kind of knowledge selected for realization of the written assignments (selection). Strong framing (F+) of I.D. on selection is applied in the cases where the students are provided with all the necessary information on the sources they are called on to study in order to complete an assignment.

b) The requirements for shaping the structure of the written essays (sequencing). When the students are called on to apply the standards for the writing of scientific articles, then a strong framing of I.D. on sequencing is implemented. When they are given freedom in the way they shape the structure of their essay, then a weak framing of I.D. on sequencing is implemented.

c) The length of time the students are allowed for the completion of their written assignment (pacing). In addition, the time the tutors are given to correct their students' assignments. For example, when the topics for the assignments are given to the students during the course of their studies and they are left with a short period of time to complete them, then a strong framing of I.D. on pacing is implemented. And,

d) The assessment criteria (criteria) that are used for correcting the written assignments. Strong framing of I.D. on criteria is implemented when the means of assessment of their written effort is explained clearly to the students.

On the actual level of the implementation of teaching, mixed pedagogical practices are applied which combine elements as much from a strong $(\mathrm{F}+)$ as from a weak framing (F-) of R.D. and I.D. (Bernstein, 1998, 2000; Koustourakis, 2017; Moore, 2013; Morais, 2002). Visible Pedagogies are implemented when the educational processes that are applied at the Open University, as well as the boundaries that define the roles of the tutor and the students, are made obvious and clear to the students (Bernstein, 1990, 2000; Moore, 2013). 
The manner in which the tutor shapes the I.D. during his teaching has an effect on the shaping of the R.D. that he promotes or which discourages the students' desire to communicate with him (Koustourakis, 2015; Morais, 2002). For example, when the criteria of evaluation are explicit to the acquirers (F+ of I.D.) a weak framing (F-) of R.D. is promoted, which regulates the tutor-students relationships (Bernstein, 1990, 2004; Morais, 2002). This is because in the case of distance learning the student who is geographically remote from the tutor can discuss with him in depth the way in which his assignment will be assessed, even having the opportunity to question the assessment he received (Koustourakis, 2015; Morais, 2002).

In this study, taking into consideration the elements of the tutors' teaching role such as the institutional habitus of the HOU (2019), which requires them to make use of the Contact Sessions to contribute to the students' better understanding of the topic of the written assignments, we will be concerned with the investigation of the formation of I.D. as much prior to the writing of the assignments as during the correction stage.

\section{Research Questions - Methodology}

In this paper we will focus our interest on the answer to the following research questions:

- What are the students' views on the shaping of Instructional Discourse that concerns written assignments during the period prior to writing them?

- What are the students' views on the shaping of Instructional Discourse during the tutors' feedback on their written assignments?

The research tool used to collect the research data was the semi-structured interview since the objective was analytical and in-depth discussion with the research subjects in order for their "voice" and experiences of the teaching dimensions of the written assignments at the HOU to be uncovered (Cohen, Manion, \& Morrison, 2008; Mason, 2011; Robson, 2007).

The research took place at the end of spring 2019 after the completion of the final Contact Session with students on the postgraduate Module "Open Distance Learning" (ODL), which is one year in length and part of the HOU Master in Education programme. The selection of the sample was made through convenient sampling (Cohen et al., 2008; Robson, 2007) on postgraduate students who: a) knew the theoretical framework of the provision of distance education since they had completed both the required written assignments as well as the study of the educational material according to the study timetable; and b) they had experience of the method of distance teaching as students were chosen who had successfully followed at least two Modules.

14 postgraduate students participated in the research, of whom 5 were men $(35.7 \%)$ and 9 women $(64.3 \%)$, and they had on average successfully completed 2.6 Modules. 2 students $(14.3 \%)$ had a Master's, 7 (50\%) were married and the average age of the students was 41.4 years old (minimum 31 years old - maximum 52 years old). The majority of the students were teachers (10 individuals $71.5 \%$, of whom 4 worked in primary education and 6 in secondary education), 3 were private employees (21.4\%) and one was unemployed $(7.1 \%)$.

During the research the interviews were sound recorded with the students' consent. In addition, the rules of morality and ethics were adhered to since the participants were informed of the aim of the research and the research procedure, they were able to leave the interview at any point, and anonymity and protection of their personal data were assured (Cohen et al., 2008; Mason, 2011; Patton, 2002). 
The data that emerged from the interviews were approached using the technique of qualitative content analysis. We took the theme as the unit of analysis, in other words, the smallest part of the content from which clear and complete meaning emerges, which is then integrated into a particular analysis category (Kripendorff 2004; Robson 2007). With the theoretical framework, the research aim and the research questions in mind, the following two analysis categories were drawn up:

1. Instructional Discourse prior to the writing of the assignment.

2. Instructional Discourse through feedback on written assignments.

\section{Presentation and Analysis of Research Findings}

Next we will proceed to the presentation, analysis and discussion of the research findings. It should be noted that for the explanation and support of individual findings, representative excerpts from the interviews will be quoted.

\subsection{Instructional Discourse prior to preparation of the written assignments}

The findings from the interviews revealed that in the HOU a strong framing of I.D. on pacing is implemented (Bernstein, 2000), regarding the time available to the students to complete the written assignments. The students assess this negatively:

"It is a usual practice for us to be given the topic for the assignment late. This has to change because tight deadlines don't allow us to adapt our study to the small amount of time available to us due to our other obligations" (Interview $5-\mathrm{I} .5)$.

"The tight deadlines we face in the HOU where the topics of the assignments are given to us shortly before the Contact Sessions, do not help us in our studies. All the topics for the assignments should be given to us at the start so that we can prepare them, bearing in mind that we have families, jobs and are following a second Module" (I.14).

Consequently, the postgraduate students in the sample would like a weak framing of I.D. on pacing (Bernstein, 2000) to be implemented for the preparation of their written assignments. In other words, in contrast to the provisions of the HOU study regulations (2019), they want the topics of the assignments to be given to them early on and to be allowed more time to complete them. As far as selection of the kind of knowledge that needs to be used in the written assignments is concerned, it emerges that a large number of the students in the sample would like a strong framing of I.D. on selection to be implemented (9 individuals, 64.3\%). This is because, as is apparent in the following representative excerpts, they believe that in the space of the limited time available for preparation of the written assignments, it should be enough that they make creative use of the main and most important parts of their educational material:

"We never had enough time to do the HOU written assignments. That's also why they shouldn't diverge from the educational material because it is difficult to search for additional material, to find time to read and to write a good assignment" (I. 2).

Nevertheless, a significant portion of students (5 individuals, 35.7\%) amongst whom are those with master's, wish to work independently to discover additional bibliographical sources to use while doing their written assignments (F- of I.D. on selection) (Bernstein, 2000).

"I want the assignments to allow me the freedom to function as a researcher and to require me to be active to complete them, finding sources beyond the 
educational material. The effort to discover knowledge has a charm to it and gives meaning to postgraduate studies" (I.4).

As far as the writing of the assignments is concerned, the majority of the students in the sample (12 individuals, $85.7 \%$ ) would like the scientific manner of structuring to be followed and in the wording of the topic for there to be clear reference to the chief sections that should be included in the texts that they will submit ( $\mathrm{F}+$ of I.D. on sequencing) (Bernstein, 2000).

"In the wording, the requirements regarding the sections that should exist in the assignments should be defined and scientific logic be applied. In other words there should be Abstract, Key Words, Introduction, Main Body, Conclusions" (I.5).

However, according to two students in the sample (14.3\%) it is not necessary in the written assignments for specific structural requirements to be followed (F- of I.D. on sequencing) (Bernstein, 2000).

"I don't like having to force my thought into a mould. I want to be free to write each assignment in the way that suits me better, responding directly to the topic" (I.9).

The students in the sample are unanimous in their view that there should be reference to the assessment criteria, even if just in a general form, in the wording of the topic of the written assignments ( $\mathrm{F}+$ of I.D. on criteria). The following excerpt is revealing:

"There should be clarity in the wording and it should be explained how our assignment will be assessed. When we know the requirements we can write an assignment that will receive a high mark and which will satisfy us" (I.13).

The views of the students in the sample are in accordance with the institutional habitus of the HOU regarding the tutors' explanation of the written assignments during the Contact Sessions. More specifically, the students want the tutors to train them and to initiate them into how to write assignments (F+ of I.D.) while implementing a weak framing of R.D. through the cultivation of good interpersonal relationships with them:

"The tutor should support us and help us with the written assignments. He should really want to approach us and get to know us in the Contact Sessions, to be friendly towards us, so that we can talk to him comfortably and ask for his help" (I.8).

More specifically, the students believe that during the $1^{\text {st }}$ Contact Session the tutor should explain the requirements for their written assignments. In the following Contact Sessions, having located the mistakes in the students' written assignments, he should use examples to help them to understand ways in which to avoid the same mistakes in the future:

"In the $1^{\text {st }}$ Contact Session (the tutor) should act like a teacher and explain to us in detail the standards our assignments should have" (I.3).

"In the $2^{\text {nd }}$ Contact Session he should show us the mistakes that we made in our $1^{\text {st }}$ essay and explain to us how to avoid them next time so that we can improve" (I. 11).

In particular, the students believe that since the tutor works, initially, in a teacher centred way and explains the requirements of the written assignments, he then needs to involve them in the learning process through group activities which will give them the practice they need to acquire writing skills:

"Once he has explained to us the parts that are needed to make up an essay and what each part should contain, he should put us to work in groups and to write for example an Introduction. He could even get us to write a small text 
using two to three sources that he gives us so we can learn to use the APA system in in-text citation" (I. 10).

Moreover, the students in the sample want the tutor to recommend supplementary bibliography that they can use in their essays (F+ of I.D. on selection) (Bernstein, 2000).

Our research findings revealed the existence of tutors who didn't help the students with the matter of the written assignments. This is because it appeared that they implemented strong hierarchical interactive relationships with the students $(\mathrm{F}+$ of R.D.) during the Contact Sessions. These are the symbolic barriers that emerge from the way the tutors see their role and the room for movement that they believe this imposes:

"On the previous Module the tutor gave general guidelines and explained the topic very superficially. When we asked him for further clarification, he told us that he couldn't say more as his role didn't permit it. It was a stressful experience because the tutor raised a wall between us" (I. 6.)

"There are tutors who just tell you a few general things. The message is that their role doesn't allow them to help you more and that putting the written assignment together is your responsibility" (I. 12).

Consequently it would appear from the excerpts above, that there are tutors who violate HOU institutional habitus and implement a strong framing of R.D. in the Contact Sessions (Bernstein, 2000). In this case the tutors don't provide the students with the necessary explanations on the topics for the assignments (F- of I.D.) and create symbolic borders that prevent communication (Koustourakis, 2015; Morais, 2002).

\subsection{Instructional Discourse through the feedback on written assignments}

The time margin of 21 days given to the tutors in the regulations of HOU to correct the written assignments is considered too long by the majority of the students (12 individuals, $85.7 \%$ ). In particular, as is apparent in the following representative excerpt, they would like the tutors to send feedback on their assignments within a week:

"I wish the tutors could correct the assignments within a week which would really be of benefit to us to learn from our mistakes, to understand the material in the Module better and become better ourselves" (I. 5).

The tutors' delay in sending feedback on the assignments not only violates the institutional habitus of the HOU, but doesn't appear to be of benefit to the students either:

"On a previous Module we had a tutor who took a long time to correct the assignments. When she sent the feedback we had forgotten the thinking behind our answers. She corrected my $3^{\text {rd }}$ essay after the $3^{\text {rd }}$ Contact Session and sent me her answer when I was trying to write the next assignment. It was insulting and for that reason I didn't bother with the comments that she made" (I.8).

The research findings show that the postgraduate students who participated in the research would like a strong framing of I.D. on pacing (Bernstein, 2000) to be implemented during the correcting of their assignments. In addition, it appears that the students would like to contribute to the modification of the HOU institutional habitus (Ingram, 2009; Thomas, 2002) requesting the shortening of the time allowed the tutors for correcting their written assignments (F- of I.D. on pacing). Moreover, the 
research revealed the existence of tutors who delayed the correction of the students' written assignments (F- of I.D. on pacing).

It should be noted that on the postgraduate Module ODL the written assignments take the form of essays and the aim in these is the implementation of the standards for the writing of scientific articles with parallel use of the APA system for in-text citations and references (F+ of I.D. on sequencing). This led to all the students in the sample who do not possess a master (12 individuals, 85.7\%) expressing the view that the tutor ought to correct errors concerning both the structure and the application of the APA system in a detailed and analytical way on the text of their assignments:

"Analytical and apt comments to be made on the essay, as well as various suggestions for how it should be written. They should even inform you of how to structure the assignment and write the references correctly" (I. 11).

Consequently, from the findings of this research it appears that the students would like a strong framing of I.D. on sequencing to be implemented (Bernstein, 2000) during the correction of their assignments. These findings reveal that the shaping of the students' views is influenced as much by the institutional habitus of the HOU (2019) which requires the tutors to make comments on the texts of the assignments, as by the pedagogical practices of ODL tutors who work in that way (Koustourakis \& Paizi, 2013; Lionarakis, 1998; Reay et al., 2005; Thomas, 2002).

Then, the majority of students in the sample (11 individuals, 78.6\%) would like the feedback they receive from the tutor to link the topic of the written assignments as much to the appropriate parts of the syllabus, as to suggestions for additional literature, the study of which contributes to the acquisition of wider knowledge of the examined issues ( $\mathrm{F}+$ of I.D. on selection) (Bernstein, 2000):

"An important element in the feedback is the explanation of what in particular the student needs to 'learn' from the material he studies and the bibliographical suggestions for going into it in more depth" (I.7).

"In the name of learning the tutor's comments should contain suggested action for study because it is likely that some students won't have understood the corresponding teaching material" (I. 13).

The findings of this research reveal that students would like Visible Pedagogies to be implemented during the correction of their written assignments (Bernstein, 2000). This is because students would like the feedback to explain to them the connections between the topic of each assignment and the teaching material they study, as well as to provide them with additional cognitive data together with important bibliographical sources, the study of which will contribute to their fuller scientific training.

The students in the sample are unanimous in wanting the feedback they receive from the tutors to explain absolutely clearly and precisely the assessment criteria for their assignments (F+ of I.D. on criteria). In fact, when this happens, the conditions are created for the development of good communicative relationships between the tutor and students (Koustourakis, 2015; Morais, 2002).

"I would like the tutor to inform me of and explain in detail the criteria he will use to correct my assignment and this helps in my interaction with him" (I. 1).

"The right assessment is detailed assessment that explains to me the criteria and means used to assess my assignment. This shows that the tutor values my effort and creates a positive climate of communication" (I. 7).

When the tutors tell the students only the grade or make only a formal and superficial reference to the way the written assignments are assessed (F- of I.D. on evaluation), 
then barriers to the students' learning effort are created and the interpersonal tutorstudent relationships are damaged.

"Grading without comments is impersonal and makes me feel that the tutor is someone who is trying to judge me in a strict way. I feel there is a gap between us and disappointment which discourages me from developing any form of communication with him" (I.6).

"It has happened often enough in the HOU that I get a grade with some superficial comment leaving me hanging and in a fog since the tutor didn't substantiate his view. I could tell his indifference and that my relationship with him was strictly formal" (I. 10).

\section{Discussion and Conclusion}

In this paper an attempt was made to investigate the attitudes of postgraduate students at the HOU, who had experience of study with the distance learning method and who had been taught the scientific knowledge on Open Distance Learning for the implementation of teaching through the preparation of and feedback on written assignments. From the study and analysis of the research material we arrive at the following findings.

The teaching intervention in essay type written assignments, which are used for the provision of distance studies, starts with the shaping of the wording of the topic. In this case it appears that the students' learning effort is aided when in the context of the implementation of Visible Pedagogies, the application of a strong framing of I.D. on selection, sequence and criteria is chosen (Bernstein, 1990, 2000). In other words the wording of the topic for each assignment needs to be absolutely clear and understandable and to guide the students regarding the important parts of the syllabus of the teaching material that they are called on to study and utilize in order to produce the assignments. In addition, the wording of each assignment should contain guiding comments on the shaping of its structure, as well as information, even just in a general form, on the assessment criteria that will be applied. Furthermore, the postgraduate students in the sample would like to see the modification of the institutional habitus of the HOU with more time being made available for the preparation of the written assignments. This is because the 3-week time margin provided (HOU, 2019) is seen by the students as too tight and restrictive (F+ of I.D. on pacing) for the success of their learning effort and the production of quality written assignments. In fact, it has been proved that providing students with sufficient time for the completion of their assignments (F- of I.D. on pacing) makes a positive contribution to their learning effort (Gibbs \& Simpson, 2005; Patton, 2000).

According to the institutional habitus of HOU (2019) the Contact Sessions are an important stage in the development of the interaction between tutor and students and in the teaching of written assignments too. The research findings revealed that in these meetings the students would like the tutors to take the initiative to reduce the distance imposed by the asymmetrical hierarchical relationships that issue from their roles (F- of R.D.) and to implement mixed pedagogical practices (Bernstein, 2000; Koustourakis, 2017; Moore, 2013). More specifically it appeared that during the contact sessions they would like the tutors to guide and inform them regarding the material they need to study in order to produce each written assignment (F+ of I.D. on selection) and the manner in which its structure should be shaped (F+ of I.D. on sequence). In addition, it is the students' wish that the tutors function initially as transmitters and teach them how to write scientific papers. They would then like the tutors to apply teaching strategies that focus on the learner with the students being 
given group - collaborative activities through which they can apply and understand the taught knowledge in order to acquire the skills necessary for the preparation of written assignments (F- of I.D.). These findings are in line with findings from other studies which reveal the need for the implementation of a strong framing of I.D. (Bernstein, 2000) to assist the learning efforts of the students through written assignments. In particular, the meetings with the students during the Contact Sessions are useful in achieving this as the tutors can communicate with their students and guide them on how to approach the written assignments and help them in the acquisition of the necessary writing skills (Chetwynd \& Dobbyn, 2011; Chokwe, 2015; Gibbs \& Simpson, 2005; Kofou, 2019; Simpson, 2018).

During the correction of the written assignments the students would like a strong framing in all the dimensions of the Instructional Discourse to be implemented. More specifically they would like the correction of their written assignments to take place as much in the form of comments on the text they submitted, as with an analytical, detailed and guiding accompanying letter, which would contribute: a) to the explanation of the way the cognitive requirements of the topic of the assignment were covered with specific references as much to the syllabus of the teaching material as to the relevant scientific bibliography (F+ of I.D. on selection); b) to the understanding of how the structure of the assignment should be shaped and the use of the APA system ( $\mathrm{F}+$ of I.D. on sequencing); and c) to the way the assignment was assessed, informing them of the precise criteria that were used ( $\mathrm{F}+$ of I.D. on criteria). In addition, the students mention the need for the adaptation of the institutional habitus of the HOU concerning the time the tutors are given to correct the written assignments. In particular, they request instead of 21 days which is the case at the HOU (2019), for shorter time margins to be put in place for the sending of feedback on their essays, which should not exceed one week ( $\mathrm{F}+$ of I.D. on pacing). This is because it appears to strengthen the students learning effort when their tutors send feedback quickly and at the same time use a friendly style in the accompanying letters, combined with encouraging and analytically informative correctional comments (F- of R.D.) (Burke \& Pieterick, 2010; Chetwynd \& Dobbyn, 2011; Morais, 2002; Poulos \& Mahony, 2008; York, 2003). When the tutor corrects the written assignments explaining to the students how to implement the standards for the writing of scientific articles and, at the same time, offering suggestions for alternative approaches to shaping the structural part, it helps them acquire scientific skills and it strengthens their ability to self-evaluate their progress in the area of writing (Anderson, 2007; Chokwe, 2015; Housnell, 2003; Nicol \& McFarlane-Dick, 2006; Walker, 2009).

Moreover, the findings of this research, revealed that the postgraduate students consider the implementation of Visible Pedagogies necessary during the correction of their written assignments, through the detailed explanation of the assessment criteria used (F+ of I.D. on criteria) (Bernstein, 1990, 2000), are in line with findings from other studies (Anderson, 2007; Price et al., 2010; Simpson, 2018; Walker, 2009; Weaver, 2006; York, 2003). When this happens and there is a real willingness on the part of the tutors to support the students (F- of R.D.) then the conditions are created for the cultivation of good and constructive interpersonal relationships, which in turn support the students' learning effort (Bernstein, 1990, 2000; Kalogiannakis \& Touvlatzis, 2015; Koustourakis, 2015; Morais, 2002). In fact, from the HOU study regulation (2019), it emerges that there is a goal to shape the professional habitus of the tutors (Bourdieu, 1986; Thomas, 2002) so that together with their teaching role, they also take on an advisory role. In this case the tutors should provide the students 
with the necessary cognitive and psychological support during their educational journey with the HOU so as to facilitate their studies at the institution. The findings of this study are in accordance with the findings of other studies that reveal the benefits that emerge for the academic success of the students from the detailed, analytic and informative feedback on their written assignments (Chokwe, 2015; Mirador, 2018; Poulos \& Mahony, 2008; Price, Handley, \& Millar, 2011; Simpson, 2018).

The students of the sample during their learning journey at the HOU encountered tutors whose pedagogical choices diverged from the institutional habitus of the institution as much at the stage prior to the writing of the assignments as after it. In the first case the particular tutors implemented strong hierarchical relationships during their interaction with the students (F+ of R.D.) in the Contact Sessions which resulted in either a superficial or entirely unhelpful approach to the demands of the written assignments. In the second case there was the delayed sending of feedback to the students (F- of I.D. on pacing) and the unclear way in which the written assignments were corrected (F- of I.D. on criteria). This, as is apparent in the findings of other scientific studies, creates dissatisfaction amongst the students and has a negative effect on their distance learning effort (Housnell, 2003; Nicol \& McFarlane-Dick, 2006; Price, Handley, Millar, \& O’Donovan, 2010; Ryan \& Henderson, 2018).

Concluding this study we should point out that the role played by the communication between the tutor and the students, which is influenced by the quality of the teaching that is carried out through the written assignments, is important. This is why the investigation of the students' views on the shaping of regulative discourse would be of interest. In other words, an investigation of the hierarchical and communicative relationships between tutor and students that are shaped based on the contents of the replies through which feedback on written assignments is provided, as well as their effects on the learning efforts and trajectory of the students.

\section{References}

Anderson, B. (2007). Independent learning. In M.G. Moore (Ed.), Handbook of distance education (pp.109-122). Mahwah, NJ: Lawrence Erlbaum Associates.

Bei, E., Mavroidis, I., \& Giossos, Y. (2020). Development of a Scale for Measuring the Learner Autonomy of Distance Education Students. European Journal of Open, Distance and Elearning, 22(2), 133-144.

Burke, D. \& Pieterick, J. (2010). Giving students effective written feedback. Berkshire: Open University Press McGraw-Hill Education.

Bernstein, B. (1990). The Structuring of Pedagogic Discourse: Vol. IV Class, Codes \& Control. London: Routledge.

Bernstein, B. (2000). Pedagogy, Symbolic control and identity. Theory, Research, Critique (Revised edition). N.Y.: Rowman \& Littlefield.

Bernstein, B. (2004). Social class and pedagogic practice. In S.J. Ball (Ed.), The RoutledgeFalmer reader in sociology of education (pp. 196-217). London: RoutledgeFalmer.

Blair, A., \& McGinty, S. (2013). Feedback-dialogues: exploring the student perspective. Assessment and Evaluation in Higher Education, 38(4), 466-476.

Bourdieu, P. (1986). The forms of capital. In J. Richardson (Ed.),Handbook of theory and research for the sociology of education (pp. 241-258). New York: Greenwood Press.

Bourdieu, P. (1990). The Logic of Practice. Cambridge: Polity.

Bourdieu, P., \& Wacquant, L.J.D. (1992). An invitation to reflexive sociology. Chicago: University of Chicago Press.

Calfoglou, C., Georgountzou, A., Hill, M., \& Sifakis, N. (2011). Factors affecting written distancelearning feedback: the tutor's perspective. Research Papers in Language Teaching and Learning, 2(1), 111-121. 
Chatzinikita, V., \& Vorvilas, G. (2019). Assessment of written feedback on educational activities: the "voice" of HOU's students. Open Education-The Journal for Open and Distance Education and Educational Technology, 15(2), 78-94.

Chetwynd, F., \& Dobbyn, C. (2011). Assessment, feedback and marking guides in distance education. Open Learning: The Journal of Open, Distance and e-Learning, 26(1), 67-78.

Chokwe, J. M. (2015). Students' and tutors' perceptions of feedback on academic essays in an open and distance learning context. Open Praxis, 7(1), 39-56.

Cohen, L., Manion, L., \& Morrison, K. (2008). Educational research methodology. Athens: Metaichmio.

Gibbs, G., \& Simpson, C. (2005). Conditions under which assessment supports students' learning. Learning and teaching in higher education, 1, 3-31.

Gravett, S., \& Petersen, N. (2002). Structuring dialogue with students via learning tasks. Innovative Higher Education, 26(4), 281-291.

Gregori, P., Martínez, V., \& Moyano-Fernández, J. J. (2018). Basic actions to reduce dropout rates in distance learning. Evaluation and program planning, 66, 48-52.

Hellenic Open University (HOU) (2019). Preparation of written assignments. Accessed April 25, 2019 from: https://www.eap.gr/el/spoudes-sto-eap/ekpaideusi/kanonismoi/kanonismos-spoudwn.

Holmberg, B. (2002). Distance Education. Theory \& Practice. Athens: Hellin Editions.

Hounsell, D. (2003). Student feedback, learning and development. In M. Slowey \& D. Watson (Eds.), Higher education and the lifecourse (pp. 67-78). Buckingham: SRHE and Open University Press.

Ingram, N. (2009). Working-class boys, educational success and the misrecognition of working-class culture. British Journal of Sociology of Education, 30(4), 412-434.

Kalogiannakis, M., \& Touvlatzis, S. (2015). Emotions experienced by learners and their development through communication with the tutor-counselor. European Journal of Open, Distance and $e$ Learning, 18(2), 37-49.

Kofou, I. (2019). A pilot study on conditions under which assessment of and feedback on written assignments affect learning. Research Papers in Language Teaching \& Learning, 10(1), 117133.

Koustourakis, G. (2006). An attempt formation of the framework for the organization and functioning of the Hellenic Open University: A sociological approach. In A. Lionarakis (Ed.), Open and Distance Education: Elements of theory and praxis (pp. 42-77). Athens: Propobos.

Koustourakis, G. (2015). Could the evaluation of written essays affect tutor-student communication in distance learning? Perceptions of Open University postgraduate students. Educational Journal of the University of Patras UNESCO Chair, 2(2), 45-58.

Koustourakis, G. (2017). Exploiting sociological knowledge in the case of schools and teachers. In Contemporary Research Trends in Preschool and First School Age (pp. 150-164). Athens: New Technologies Editions.

Koustourakis, G., \& Paizis, N. (2013). A sociological approach of the Contact Sessions in the case of the Module DEO34 'Economic Analysis and Policy' of the undergraduate program Business Administration of the Hellenic Open University. In A. Lionarakis (Ed.). Proceedings $7^{\text {th }}$ International Conference in Open and Distance Learning 'Learning Methodologies' (Volume 1, pp. 23-36). Athens: Editions of the Hellenic Network of Open and Distance Education

Koustourakis, G., Panagiotakopoulos, C., \& Vergidis, D. (2008). A Contribution to the Hellenic Open University: Evaluation of the pedagogical practices and the use of ICT on distance education. The International Review of Research in Open and Distance Learning, 9(2), 1-18.

Kreonidou, G., \& Kazamia, V. (2019). Assignment feedback in distance education: How do students perceive it?. Research Papers in Language Teaching and Learning, 10(1), 134-153.

Kripendorff, K. (2004). Content Analysis. An Introduction to Its Methodology. Thousant Oaks: Sage Publications.

Lionarakis, A. (1998). Continuous communication and evaluation of the student. In A. Kokkos \& A. Lionarakis (Eds.), Open Distance Learning. Teachers - students relations (Vol. B', pp. 241-253). Patras: $\mathrm{HOU}$

Lizzio, A., \& Wilson, K. (2008). Feedback on assessment: students' perceptions of quality and effectiveness. Assessment \& Evaluation in Higher Education,33(3), 263-275.

Maliotaki, D. (2019). Let feedback make the connection: Battling isolation in Distance Learning-The case of the MEd in TESOL students of the Hellenic Open University. Research Papers in Language Teaching and Learning, 10(1), 188-209.

Mason, J. (2011). The conduct of qualitative research. Athens: Pedio. 
Mirador, J. (2018). Investigating' Criticality' in written assignments of postgraduate students. Writing \& Pedagogy, 10(1-2), 61-92.

Moore, R. (2013). Basil Bernstein. The thinker and the field. London and N.Y.: Routledge.

Morais, A.M. (2002). Basil Bernstein at the Micro Level of the Classroom. British Journal of Sociology of Education, 23(4), 559-569.

Nicol, D., \& McFarlane-Dick, D. (2006). Formative assessment and self-regulated learning: A model and seven principles of good feedback practice. Studies in Higher Education, 30(2), 369-386.

Patton, M. A. (2000). The importance of being flexible with assignment deadlines. Higher Education in Europe, 25(3), 417-423.

Patton, M. (2002). Qualitative research \& evaluation methods. London: Sage Publications.

Pierrakeas, C., Xenos, M., Panagiotakopoulos, C., \& Vergidis, D. (2004). A comparative study of dropout rates and causes for two different distance education courses. The International Review of Research in Open and Distance Learning, 5(2), 1-15.

Poulos, A., \& Mahony, M. (2008). Effectiveness of feedback: The students' perspective. Assessment \& Evaluation in Higher Education, 33(2), 143-154.

Price, M., Handley, K., Millar, J., \& O'Donovan, B. (2010). Feedback: all that effort, but what is the effect?. Assessment \& Evaluation in Higher Education, 35(3), 277-289.

Price, M., Handley, K., \& Millar, J. (2011). Feedback: Focusing attention on engagement. Studies in higher education, 36(8), 879-896.

Race, P. (1999). The Handbook of Open Learning. Athens: Metaixmio.

Reay, D., David, M.E., \& Ball, S.J. (2005). Degrees of Choice. Stoke on Trent: Trentham Books.

Robertson, S. I. (2014). Academic essay writing as imitative problem solving: examples from distance learning. Assessment \& Evaluation in Higher Education, 39(3), 263-274.

Robson, C. (2007). Real world research. A means for social scientists and research professionals. Athens: Gutenberg.

Ryan, T., \& Henderson, M. (2018). Feeling feedback: students' emotional responses to educator feedback. Assessment \& Evaluation in Higher Education, 43(6), 880-892.

Simpson, O. (2018). Supporting students in online, open and distance learning. N.Y.: Routledge.

Smyth, E., \& Banks, J. (2012). 'There was never really any question of anything else': young people's agency, institutional habitus and the transition to higher education. British Journal of Sociology of Education, 33(2), 263-281.

Thomas, L. (2002). Student retention in higher education: the role of institutional habitus. Journal of Education Policy, 17(4), 423-442.

Walker, M. (2009). An investigation into written comments on assignments: Do students find them usable? Assessment and Evaluation in Higher Education, 34(1), 67-78.

Weaver, M. R. (2006). Do students value feedback? Student perceptions of tutors' written responses. Assessment \& Evaluation in Higher Education, 31(3), 379-394.

Yorke, M. (2003). Formative assessment in higher education: Moves towards theory and the enhancement of pedagogic practice. Higher Education, 45(4), 477-501. 